\title{
Group-Based Trajectory Modeling (Nearly) Two Decades Later
}

\author{
Daniel S. Nagin • Candice L. Odgers
}

Published online: 12 October 2010

(C) The Author(s) 2010. This article is published with open access at Springerlink.com

Nearly two decades have passed since the publication of "Age, Criminal Careers, and Population Heterogeneity: Specification and Estimation of a Nonparametric Mixed Poisson Model" by Nagin and Land (1993). In that article Nagin and Land laid out a statistical method that has come to be called group-based trajectory modeling. The principle objective of the paper was to address issues related to the "hot topic" of the time-the criminal career debate-not to lay out a new statistical methodology. As described in the paper's abstract, these issues were: "First, is the life course of individual offending patterns marked by distinctive periods of quiescence? Second, at the level of the individual, do offending rates vary systematically with age? In particular, is the age-crime curve single peaked or flat? Third, are chronic offenders different from less active offenders? Do offenders themselves differ in systematic ways?"

Figure 1 reports Nagin's (2005) updated version of the trajectories reported in Nagin and Land (1993). The analysis is based on the classic dataset assembled by Farrington and West (1990), which includes data on convictions from age 10 to 32 in a sample of over 400 males from a poor neighborhood in London, England. A four group model, analyzed using the zero-inflated Poisson modeling option, was found to best fit the data. The largest trajectory group accounted for $69.5 \%$ of the population, and was composed of individuals who generally had no convictions. The three offending trajectories included an adolescentlimited group (12.4\% of the population), which peaked sharply in late adolescence, and then declined to a near zero rate of offending by age 20 , a high chronic trajectory $(5.9 \%$ of the population) with a high-humped shaped trajectory and a low rate chronic trajectory that accounted for the remaining $12.2 \%$ of the population. Also, shown in the figure are $95 \%$ confidence intervals around each trajectory.

The dominant legacy of Nagin and Land (1993), however, was not its answers to the specific questions listed in the abstract but the methodology itself. A review of applications

\footnotetext{
D. S. Nagin $(\square)$

The School of Public Policy \& Management, Heinz College, Carnegie Mellon University, Pittsburgh, PA, USA

e-mail: dn03@andrew.cmu.edu

C. L. Odgers

School of Social Ecology, University of California, Irvine, Irvine, CA, USA
} 


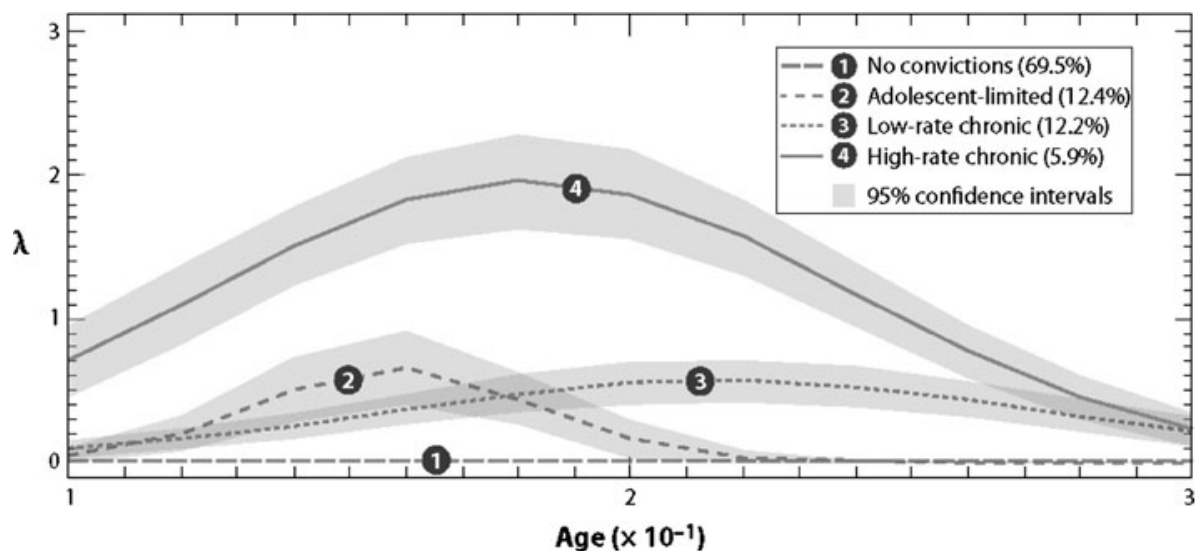

Fig. 1 Trajectories of convictions (London data)

of group-based trajectory modeling (GBTM) by Piquero (2008) identified more than 80 applications in criminology. There are even larger numbers of applications of GBTM outside of criminology. As noted by Bushway and Weisburd (2006), GBTM is one the few examples of a statistical method with origins in criminology that has come to be widely used by other disciplines. In a recent review of GBTM for clinical psychologists (Nagin and Odgers 2010) the authors documented a rapid rise in the application of trajectory based models in clinical research; a PSYC INFO literature review indicated that between 2000 and 2008 the application of GBTMs increased from 8 to 80 publications per year in clinically relevant journals such as the Journal of Clinical and Consulting Psychology, Child Development, Addiction and the Journal of Abnormal Child Psychology. Within this area, trajectory models have been applied to understand the etiology and developmental course of a number of different types of disorders, including: depression (Dekker et al. 2007; Mora et al. 2009), inattention/hyperactivity (Jester et al. 2008), post-traumatic stress disorder (Orcutt et al. 2004), substance abuse (Hu et al. 2008) and conduct disorder (Odgers et al. 2008b). More recently, group-based models have been extended to capture heterogeneity in treatment responses to clinical and randomized trials (Brown et al. 2008; Peer and Spaulding 2007) and have been leveraged to facilitate causal inference in epidemiological observational studies where randomization to treatment conditions is not possible (Haviland et al. 2007; Haviland et al. 2008; Odgers et al. 2008a). There have also been numerous applications of GBTM in medical journals including the New England Journal of Medicine, Archives of General Psychiatry, Pediatrics, Journal of Adolescent Psychology and Psychiatry that address not only the developmental course of psychiatric disorders but also target biomarkers such as body mass index (Mustillo et al. 2003), cortisol levels (Van Bokhoven et al. 2005; Van Ryzin et al. 2009), as well as indicators of disability in elderly populations (Gill et al. 2010).

What accounts for the rapid adoption of GBTM in such diverse settings? In many ways, it is not surprising that GBTM has been embraced by clinical researchers interested in the developmental course of psychiatric and physical disorders. GBTM maps closely on how researchers conceptualize the growth and development of a wide range of phenomena; provide an empirical means of identifying clusters of individuals following both typical and atypical courses of development; and offer a new set of tools for evaluating individual variation in response to interventions and randomized trials. With respect to theory-method 
Table 1 Trajectory group profiles (London data)

\begin{tabular}{lllll}
\hline Variable & \multicolumn{3}{l}{ Group } \\
\cline { 2 - 5 } & $\begin{array}{l}\text { Rare } \\
\text { Adolescent } \\
\text { limited }\end{array}$ & $\begin{array}{l}\text { Low } \\
\text { chronic }\end{array}$ & $\begin{array}{l}\text { High } \\
\text { chronic }\end{array}$ \\
\hline Low IQ (\%) & 16.3 & 23.5 & 34.8 & 43.5 \\
Poor parenting (\%) & 18.4 & 29.4 & 30.4 & 47.8 \\
High risk taking (\%) & 21.2 & 47.1 & 37.0 & 69.5 \\
Parents with criminal record (\%) & 18.0 & 43.5 & 33.3 & 60.9 \\
\hline
\end{tabular}

fit, there is a long tradition of group-based theorizing about both normal and pathological development in psychology. Examples include theories of personality development (Caspi 1998), learning (Holyoak and Spellman 1993), language and conceptual development (Markman 1989), mental disorders such as depression (Kasen et al. 2001), eating disorders (Tyrka et al. 2000), alcoholism (Cloninger 1987) conduct disorder and delinquency (Loeber 1991; Moffitt 1993; Patterson et al. 1989) and anxiety (Cloninger 1986) as well as the development of prosocial behaviors such as conscience (Kochanska 1997).

But what accounts for its widespread use among non-clinical researchers, most specifically by criminologists? In part the application of GBTMs within this context reflects the influence of developmental psychopathology research on what has come to be called developmental criminology. Leading researchers in this tradition-David Farrington, Magda and Rolf Loeber, and Terrie Moffitt—straddle criminology and developmental psychology and have been instrumental in encouraging the field to develop and test theories related to the developmental course of antisocial behavior and crime across the lifespan. To this end, GBTM is ideally suited for analyzing the influential taxonomic theories of antisocial and delinquent behavior of Moffitt (1993) and Patterson et al. (1989, 1998).

We conjecture, however, that GBTMs widespread use in criminology is affected by more than just the influence of imminent psychologists who also double as criminologists. A hallmark of modern longitudinal studies is the variety and richness of measurements that are made about the study's subjects and their circumstances. Less often acknowledged is the fact that this abundance of information is accompanied by a difficult companioncomplexity — and the desire among researchers to disentangle population heterogeneity and move beyond a 'one size fits all' approach to describing development across the lifespan. Commonly, researchers are confronted with the dilemma of how best to explore and test theories of development within these rich sets of measurements without increasing the analytical complexity to the point where the lessons to be learned from the data are lost on them and their audience. By segmenting the data into trajectory groups, the group-based approach to studying development, provides an empirical means of summarizing large amounts of data in an easily comprehensible fashion and for testing long standing developmental theories with a taxonomic dimension.

Table 1 illustrates how trajectory models can be leveraged to summarize large amounts of data collected across development and test theories regarding the origins of antisocial behavior for each of the four trajectory groups shown in Fig. 1. For example, the high chronics, on average, were most likely to have a low IQ, to have had at least one parent with a criminal record, to have had poor parenting, and to have engaged in risky activities. Conversely, the rare group was lowest on these risk factors. The contrasting characteristics of the chronic and rare groups are strongly consistent with much prior research. The 
adolescent-limited and low-chronic groups fall in between but the differences between these two groups form a more complex pattern. The low chronics have a higher incidence of low IQ than the adolescent-limited group but have a lower incidence of parental criminality and risk-taking behavior. This suggests the possibility of a difference in the etiology that underlies the criminality of these two groups. The profiles illustrate the utility of GBTM in two important functions that transcend specific subject matter: (1) communication of research findings in an easily interpretable format and (2) identification of subtle but significant variations across trajectory groups in their predictors and outcomes.

Extensions to of the basic model also lend themselves to achieving these two objectives. These extensions include modeling predictors of probability of trajectory group membership, estimating the possible influence of other covariates beyond age or time on the trajectory of the phenomenon under study, and assessing the inter-relationship of two or more trajectories of distinct but related outcomes. Examples of the last modeling capacity is modeling the comorbidity of trajectories of delinquency, drug use, and sexual activity or the interconnection of trajectories of childhood physical aggression and trajectories of adolescent violent delinquency (Nagin 2005). For an extended discussion of these modeling capabilities see Nagin (2005) or Nagin and Odgers (2010; forthcoming) and for discussion of the software capabilities for estimating such models see Jones et al. (2001) and Jones and Nagin (2007).

How has the application of GBTM advanced theory and method development in the field of criminology? Before attempting an answer to this question, a caveat emptor is in order. All statistical methods are devices for summarizing data. Grouping longitudinal data according to trajectories groups is but one form of data summary, which carries the important benefit of mapping closely to how we conceptualize the development of a wide range of behaviors, emotions and related phenomenon. Other popular methods for capturing this type of growth and change over time include grouping by clinical cut-offs, conventional growth curve modeling, and growth mixture modeling. See Nagin and Odgers (2010; forthcoming) for a discussion of these alternatives. All of these methods share the common objective of explaining population differences in the developmental course of the phenomenon of interest. Thus, no method should have hegemony. Still grouping by trajectory group does uniquely facilitate addressing some types of issues. In the discussion which follows we describe three findings that have emerged from GBTM analysis, that in our judgment, are important to criminology and highlight the strengths of the method.

The examples featured below all relate to what is perhaps the most influential empirical regularity in criminology - the age-crime curve. It has been repeatedly demonstrated that age specific arrest rates rise steady from early adolescence, peak at about age 18 and steadily decline thereafter (Hirschi and Gottfredson 1983). While there are variations in this pattern by crime type, time and place, the regularity is remarkably robust (Farrington 1986). We describe this regularity as influential because it is hard to overstate how much research and theorizing in criminology has been committed to explaining the rising tide of misbehavior during adolescence and its subsequent decline from early adulthood onward.

At least with regards to violence, the research collaboration of Nagin and Tremblay that made extensive use of GBTM challenges the assumption that the onset of violence begins in adolescences (c.f., Côté et al. 2002; Lacourse et al. 2002; Nagin et al. 2003; Nagin and Tremblay 1999, 2001). Figure 2 from Nagin and Tremblay (1999) reports trajectories of physical aggression from age 6 to 15 based on a prospective longitudinal study of about 1,000 white, French-speaking males from low socio-economic status neighborhoods in Montreal. A group called "lows" is composed of individuals who display little or no physically aggressive behavior. This group is estimated to compose about $15 \%$ of the 


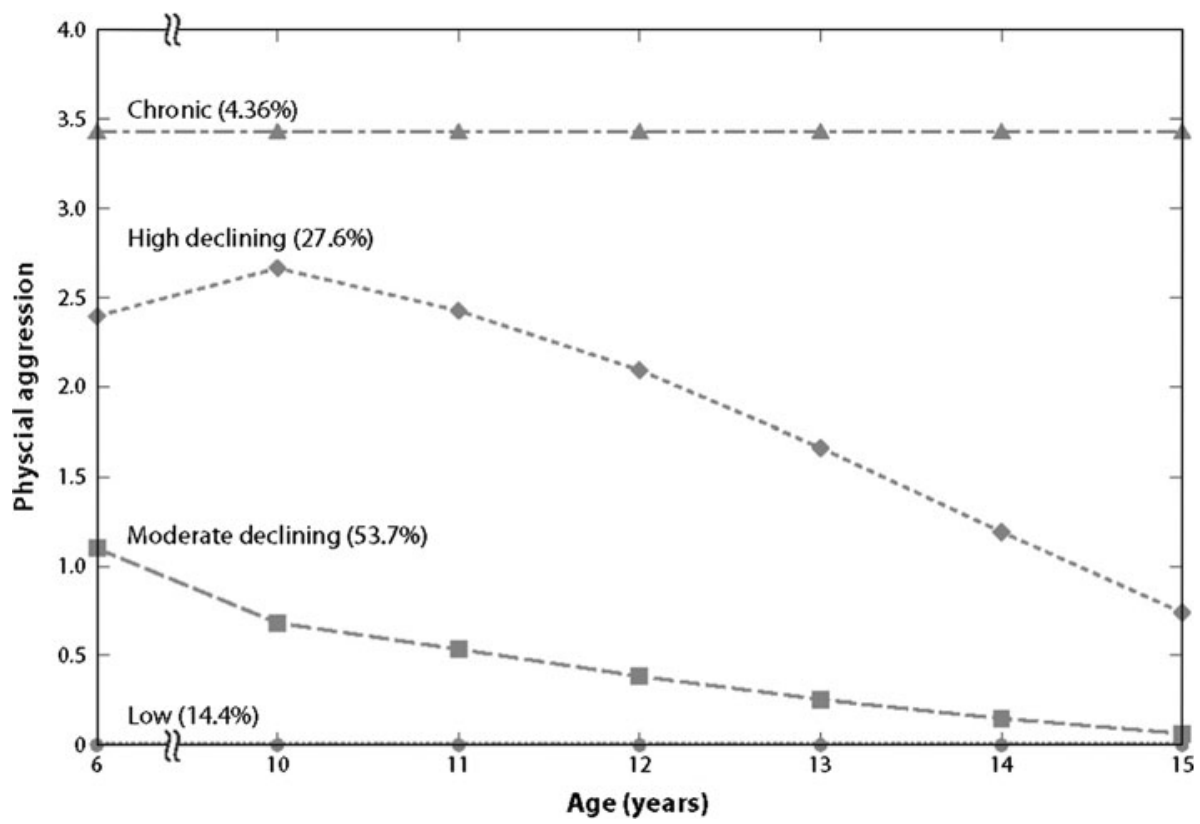

Fig. 2 Trajectories of physical aggression (Montreal data)

sampled population. A second group, composing about $50 \%$ of the population, is best labeled "moderate declining." At age 6, boys in this group displayed a modest level of physical aggression, but by age 10 they had largely desisted. A third group, composing about $30 \%$ of the population, labeled "high declining", starts off scoring high on physical aggression at age 6 but scores far lower by age 15. Notwithstanding this marked decline, at age 15 they continue to display a modest level of physical aggression. Finally, there is a small group of "chronics," making up less than 5\% of the population, who display high levels of physical aggression throughout the observation period.

These trajectories are notable both for what is present and what is not present. As for what is present, all of the trajectories are stable or declining from age 6 on. Thus, over the period from age 6 to 15 there is no evidence of rising physical aggression even among a small sub-population in these data. As for what is not present, we see no evidence of late onset-like trajectories of physical aggression, namely a trajectory that rises from a zero or negligible level at some point between 6 and 15. Because the trajectories are at their highest at age 6 , this suggests that to understand the developmental origins of physical aggression in these boys we need to look back in time prior to age 6 rather than forward in time into their adolescence. Indeed much research confirms this supposition (Tremblay 2010). While developmental psychologists have long observed elevated mean levels of aggression in early childhood, trajectory modeling has provided a tool for showcasing the developmental trends in aggression over time for both the entire population and for key subgroups of children. The absence of late onset-type trajectories of physical aggression is not unique to these Montreal males. A follow-up analysis of five additional prospective longitudinal studies-one more from Canada, two from New Zealand, and two from the US-again found no evidence of the onset of physical aggression after age 6 (Broidy et al. 2003). Arguably, the application of GBTMs has helped to extend theorizing about the age-crime 


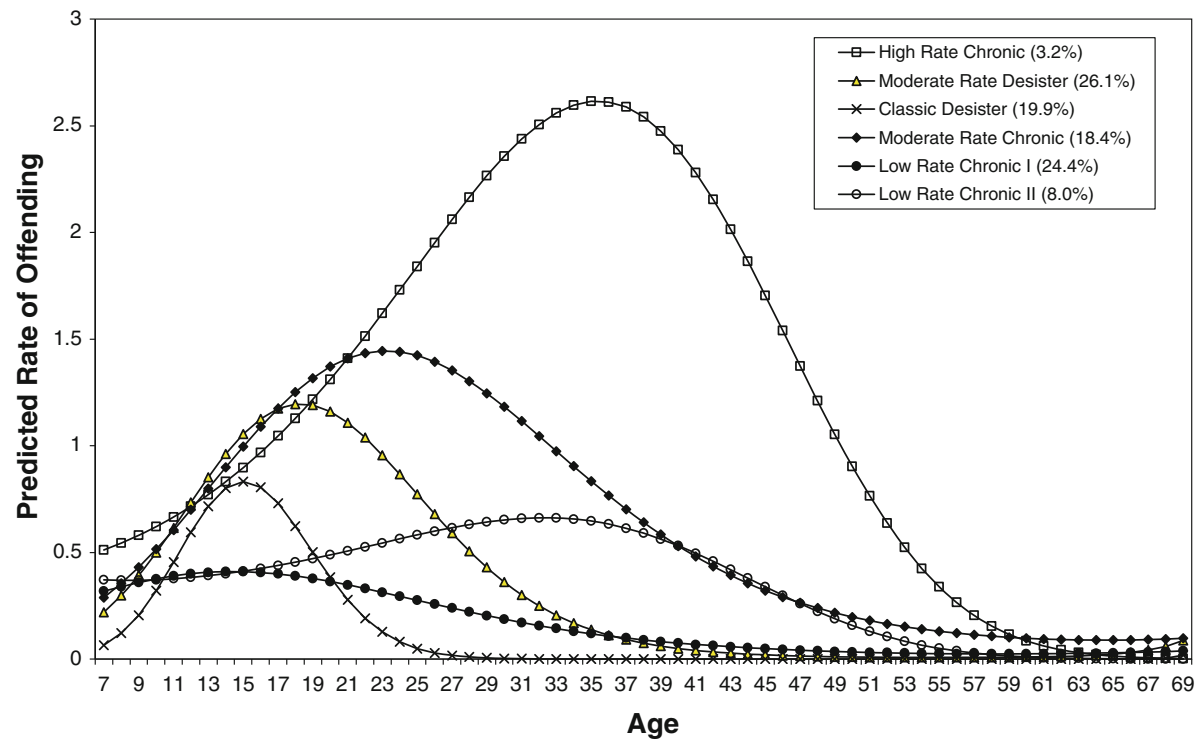

Fig. 3 Official arrest trajectories-Glueck Males-Ages 7-70. (Source: Sampson and Laub 2003, p. 582, Fig. 11)

(or age-aggression curve) beyond the typical age period relied on by criminologists, who are working primarily with official arrest records that by design censor childhood behaviors.

It is important to recognize that the age-crime curve is only a population average. There are potentially large individual level variations about the population average. Just as important individual level trajectories may follow markedly different time paths. The trajectory groups are properly understood as latent strata in longitudinal data; that is collections of individuals following approximately the same developmental course. From this perspective, GBTM is a useful methodology for identify groups of individual following markedly different trajectories of offending.

To illustrate, Fig. 3 from Eggleston et al. (2004) reports trajectories of arrests based on the Glueck and Glueck (1950) archive and the follow-up data described in Sampson and Laub (1993) and Laub and Sampson (2003). While the total sample is composed of 500 juvenile delinquent males selected from two reform schools in Massachusetts and 500 matched non-delinquent males selected from the Boston public school system, this analysis focuses on the delinquent sample. Eggleston et al. found that the six group model shown in Fig. 3 best represented the trajectories of arrest from age 7 to 70 . The most striking feature of the model is the wide variation across trajectory groups in the peak rates of offending as measured by arrest. While all trajectories follow a pattern of rise and then fall, only two trajectories - the classic desisters and the moderate-rate desisters-representing only half of the sample reach their peak rate of offending as teenagers. One small group called the high rate chronics reaches their peak offending rate at about age 40. Just as important, a sizable proportion of the sample is offending at elevated rates well past age 30 . The Eggleston et al. analysis illustrates that there is no one age-crime curve to be explained, a finding that has been repeatedly documented by other applications of GBTM (cf. Bushway et al. 2003; Brame et al. 2001; Blokland et al. 2005; Odgers et al. 2008b; Piquero et al. 2001) including the original analysis by Nagin and Land (1993). This collection of diverse results also illustrates the importance of understanding sample selection when applying 
GBTMs and exercising caution when comparing trajectory solutions across normative versus high-risk or delinquent samples. That is, one should not expect the numbers, size and shapes of trajectory groups to remain constant across samples from different populations.

The third important finding that has emerged from GBTM is ironic because it has also been the source of the criticism of GBTM that trajectory groups imply predestined paths of behavior. To the contrary, GBTM lends itself to demonstrating that past is not necessarily prologue to the future. An important aim of the Eggleston et al. (2004) analysis was to demonstrate this point. Their demonstration involved comparing models based on successively longer periods of follow-up. The model for the shortest period of follow-up was from age 7 to 24 and the longest was for age 7-70 as reported in Fig. 3. The models nicely demonstrate that over time trajectory groups can split off. For example, as shown in Fig. 3 up to age 20 the high rate chronics $(3.2 \%)$, moderate rate chronics $(18.4 \%)$, and moderate rate desisters $(18.4 \%)$ are indistinguishable. Only after age 20 do the trajectories of the moderate rate desisters and the moderate rate chronics progressively split off from the small group of high rate chronics. In total these three groups compose an estimated $47.7 \%$ of the population yet there was only a .067 (=.032/.477) chance of their combined membership following the high chronic trajectory. What better way of showing that past is not necessarily prologue to the future than to isolate the points where trajectory paths diverge over time?

We believe that GBTM offers criminology a valuable statistical tool for the longitudinal study of crime phenomena. Looking forward, there are a number of intriguing possibilities for the further application of GBTM in criminology. Some examples include applications of GBTMs to answer longstanding substantive questions related to heterogeneity in the ebb and flow of self-control and involvement with delinquent peers with age. There is also the potential to begin unpacking questions related to the "co-morbidity" of trajectories of based on official records with those based on self reports using dual trajectory modeling. One of the most recent, and perhaps most exciting, extensions of these models has been the combination of GBTMs with propensity score modeling to facilitate causal inference in longitudinal studies where randomization to treatment condition is not possible-as is the case in the majority of criminological studies (see Haviland et al. 2007). To maximize the impact of these applications, additional methodological work, such as that in Brame et al. (2006), is also required to refine tests of model fit and selection.

The appeal of GBTMs for the future of criminological research lies in the potential for the innovative application of trajectory models - on their own, in conjunction with other statistical methods or embedded within creative study designs-while carefully considering the perils and pitfalls inherent in the use of any methodology.

Acknowledgments This work was funded in part by the National Science Foundation (SES-99113700; SES-0647576) the National Institute of Mental Health (RO1 MH65611-01A2) and the National Institute on Aging (R01 AG032282-02). Candice Odgers is a William T. Grant Scholar.

Open Access This article is distributed under the terms of the Creative Commons Attribution Noncommercial License which permits any noncommercial use, distribution, and reproduction in any medium, provided the original author(s) and source are credited.

\section{References}

Blokland A, Nagin DS, Nieuwbeerta P (2005) Life span offending trajectories of a Dutch conviction cohort. Criminology 43:919-954 
Brame R, Mulvey EP, Piquero AR (2001) On the development of different kinds of criminal activity. Sociol Methods Res 29:319-341

Brame R, Nagin DS, Wasserman L (2006) Exploring some analytical characteristics of finite mixture models. J Quant Criminol 22:31-60

Broidy LM, Nagin D, Tremblay RE, Brame B, Dodge K, Fergusson D, Horwood J, Loeber R, Laird R, Lynam D, Moffitt T, Bates JE, Pettit GS, Vitaro F (2003) Developmental trajectories of childhood disruptive behaviors and adolescent delinquency: a six site, cross national study. Dev Psychol 39:222-245

Brown CH, Wang W, Kellam SG, Muthen BO, Petras H et al (2008) Methods for testing theory and evaluating impact in randomized field trials: intent-to-treat analyses for integrating the perspectives of person, place, and time. Drug Alcohol Depend 95:S74-S104

Bushway SD, Weisburd D (2006) Acknowledging the centrality of quantitative criminology in criminology and criminal justice. Criminologist 31:1-3

Bushway SD, Thornberry TP, Krohn MD (2003) Desistance as a developmental process: a comparison of static and dynamic approaches. J Quant Criminol 19:129-153

Caspi A (1998) Personality development across the life course. In: Eisenberg N, Daom W (eds) Handbook of child psychology. Wiley, New York, pp 311-388

Cloninger CR (1986) A unified biosocial theory of personality and its role in the development of anxietystates. Psychiatr Dev 4:167-226

Cloninger CR (1987) A systematic method for clinical description and classification of personality variants-a proposal. Arch Gen Psychiatry 44:573-588

Côté S, Tremblay RE, Nagin D, Zoccolillo M, Vitaro F (2002) The development of impulsivity, fearfulness, and helpfulness during childhood: patterns of consistency and change in the trajectories of boys and girls. J Child Psychol Psychiatry 43:609-618

Dekker MC, Ferdinand RF, van Lang NDJ, Bongers IL, van der Ende JD, Verhulst FC (2007) Developmental trajectories of depressive symptoms from early childhood to late adolescence: gender differences and adult outcome. J Child Psychol Psychiatry 48:657-666

Eggleston EP, Laub JH, Sampson RJ (2004) Methodological sensitivities to latent class analysis of longterm criminal trajectories. J Quant Criminol 20:1-26

Farrington DP (1986) Age and crime. In: Tonry M, Morris N (eds) Crime and justice: an annual review of research, vol 7. University of Chicago Press, Chicago

Farrington DP, West DJ (1990) The Cambridge study in delinquent development: a prospective longitudinal study of 411 males. In: Kerner HJ, Kaiser G (eds) Criminality: personality, behavior, and life history. Springer-Verlag, Berlin, pp 115-138

Gill TM, Gahbauer EA, Han L, Allore HG (2010) Trajectories of disability in the last year of life. N Engl J Med 362:1173-1180

Glueck S, Glueck E (1950) Unraveling juvenile delinquency. The Commonwealth Fund, New York

Haviland AM, Nagin DS, Rosenbaum PR (2007) Combining propensity score matching and group-based trajectory analysis in an observational study. Psychol Methods 12:247-267

Haviland AM, Rosenbaum PR, Nagin DS, Tremblay RE (2008) Combining group-based trajectory modeling and propensity score matching for causal inferences in nonexperimental longitudinal data. Dev Psychol 44:422-436

Hirschi T, Gottfredson MR (1983) Age and the explanation of crime. Am J Sociol 89:552-584

Holyoak KJ, Spellman BA (1993) Thinking. Annu Rev Psychol 44:265-315

Hu MC, Muthen B, Schaffran C, Griesler PC, Kande IDB (2008) Developmental trajectories of criteria of nicotine dependence in adolescence. Drug Alcohol Depend 98:94-104

Jester JM, Nigg JT, Buu A, Puttler LI, Glass JM et al (2008) Trajectories of childhood aggression and inattention/hyperactivity: differential effects on substance abuse in adolescence. J Am Acad Child Adolesc Psychiatry 47:1158-1165

Jones BL, Nagin DS (2007) Advances in group-based trajectory modeling and a SAS procedure for estimating them. Sociol Methods Res 35:542-572

Jones B, Nagin DS, Roeder K (2001) A SAS procedure based on mixture models for estimating Sevelopmental trajectories. Sociol Methods Res 29:374-393

Kasen S, Cohen P, Skodol AE, Johnson JG, Smailes E, Brook JS (2001) Childhood depression and adult personality disorder-alternative pathways of continuity. Arch Gen Psychiatry 58:231-236

Kochanska G (1997) Multiple pathways to conscience for children with different temperaments: from toddlerhood to age 5. Dev Psychol 33:228-240

Lacourse R, Côte S, Nagin DS, Vitaro F, Brendgen M, Tremblay RE (2002) A longitudinal-experimental approach to testing theories of antisocial behavior development. Dev Psychopathol 14:909-924 
Laub JH, Sampson R (2003) Shared beginnings, divergent lives: delinquent boys to age 70. Harvard University Press, Cambridge, Mass

Loeber R (1991) Questions and advances in the study of developmental pathways. In: Cicchetti D, Toth S (eds) In rochester symposium on developmental psychopathology. University. of Rochester Press, Rochester, pp 97-116

Markman EM (1989) Categorization and naming in children: problems of induction. MIT Press, Cambridge

Moffitt TE (1993) Adolescence-limited and life-course-persistent antisocial-behavior-a developmental taxonomy. Psychol Rev 100:674-701

Mora PA, Bennett IM, Elo IT, Mathew L, Coyne JC, Culhane JF (2009) Distinct trajectories of perinatal depressive symptomatology: evidence from growth mixture modeling. Am J Epidemiol 169:24-32

Mustillo S, Worthman C, Erkanli A, Keeler G, Angold A, Costello EJ (2003) Obesity and psychiatric disorder: developmental trajectories. Pediatrics 111:851-859

Nagin D (2005) Group-based modeling of development. Harvard University. Press, Cambridge

Nagin DS, Land KC (1993) Age, criminal careers, and population heterogeneity-specification and estimation of a nonparametric, mixed poisson model. Criminology 31:327-362

Nagin DS, Odgers CL (2010) Group-based trajectory modeling in clinical research. In: Nolen-Hoekland S, Cannon T, Widger T (eds) Annual review of clinical psychology. Annual Reviews, Palo Alto, CA

Nagin DS, Tremblay RE (1999) Trajectories of boys' physical aggression, opposition, and hyperactivity on the path to physically violent and nonviolent juvenile delinquency. Child Dev 70:1181-1196

Nagin DS, Tremblay RE (2001) Parental and early childhood predictors of persistent physical aggression in boys from kindergarten to high school. Arch Gen Psychiatry 58(4):389-394

Nagin DS, Pagani LS, Tremblay RE, Vitaro F (2003) Life course turning points: the effect of grade retention on physical aggression. Dev Psychopathol 15:343-361

Odgers CL, Caspi A, Nagin DS, Piquero AR, Slutske WS et al (2008a) Is it important to prevent early exposure to drugs and alcohol among adolescents? Psychol. Sci. 19:1037-1044

Odgers CL, Moffitt TE, Broadbent JM, Dickson N, Hancox RJ et al (2008b) Female and male antisocial trajectories: from childhood origins to adult outcomes. Dev Psychopathol 20:673-716

Orcutt HK, Erickson DJ, Wolfe J (2004) The course of PTSD symptoms among Gulf War veterans: a growth mixture modeling approach. J Trauma Stress 17:195-202

Patterson GR, Debaryshe BD, Ramsey E (1989) A developmental perspective on antisocial-behavior. Am Psychol 44:329-335

Patterson GR, Forgatch MS, Yoerger KL, Stoolmiller M (1998) variables that initiate and maintain an earlyonset trajectory for juvenile offending. Dev Psychopathol 10:531-547

Peer JE, Spaulding WD (2007) Heterogeneity in recovery of psychosocial functioning during psychiatric rehabilitation: an exploratory study using latent growth mixture modeling. Schizophr Res 93:186-193

Piquero AR (2008) Taking stock of developmental trajectories of criminal activity over the life course. In: Liberman A (ed) The long view of crime: a synthesis of longitudinal research. Springer, New York, pp 23-78

Piquero AR, Blumstein A, Brame R, Haapenen R, Mulvey EP, Nagin DS (2001) Assessing the impact of exposure time and incapacitation on longitudinal trajectories of criminal offending. $\mathrm{J}$ Adoles Res 16:54-74

Sampson RJ, Laub JH (1993) Crime in the making: pathways and turning points through life. Harvard University Press, Cambridge, Mass

Sampson RJ, Laub JH (2003) Life course desisters? Trajectories of crime among delinquent boys followed to age 70. Criminology 41:555-592

Tremblay RE (2010) Developmental origins of disruptive behaviour problems: the 'original sin' hypothesis, epigenetics and their consequences for prevention. J Child Psychol Psychiat 51:341-367

Tyrka AR, Graber JA, Brooks-Gunn J (2000) The development of disordered eating: correlates and predictors of eating problems in the context of adolescence. In: Sameroff JA, Lewis M, Miller SM (eds) Handbook of developmental psychopathology. Kluwer, New York, pp 607-624

Van Bokhoven I, Van Goozen SHM, Van Engeland H, Schaal B, Arseneault L, Séguin J, Nagin DS, Vitaro F, Tremblay RE (2005) Salivary cortisol and aggression in a population-based longitudinal study of adolescent males. J Neural Transm 112:1083-1096

Van Ryzin MJ, Chatham M, Kryzer E, Kertes DA, Gunnar R (2009) Identifying atypical cortisol patterns in young children: the benefits of group-based trajectory modeling. Psychoneuroendocrinology 34:50-61 